\title{
TRATAMENTOS PRÉ-GERMINATIVOS \\ DE SEMENTES DE ESPÉCIES FLORESTAIS AMAZŌNICAS. \\ I - ANGELIM PEDRA (DINIZIA EXCELSA DUCKE \\ - LEGUMINOSAE, MIMOSOIDEAE).
}

\author{
Benedito Vastano Jr. * \\ Antenor Pereira Barbosa * \\ Antonio Natal Gonçalves **
}

\section{Resumo}

$\mathrm{O}$ angelim pedra (Dinizia excelsa Ducke - Leguminosae) é uma essência florestal da região amazônica de importância econômica, mas pouco estudada. Suas sementes apresentam dormência e heterogeneidade de germinação, o que dificulta a atividade de formação de mudas. Os autores, no presente trabalho, estudam métodos de quebra de dormência destas sementes, e a influência do tegumento na germinação. Recomendam ainda para a quebra da dormência, escarificações com ácido sulfúrico, escarificações mecânicas ou ação térmica.

\section{INTRODUÇĀO}

$O$ angelim pedra, segundo Loureiro et al., (1979) é uma árvore de grande porte, atingindo uma altura até de $60 \mathrm{~m}$, com DAP de até 2 ou mais metros. Sua madeira é empregada para a fabricação de chapas decorativas, dormentes, construção civil e naval, macetas, marcenaria, carpintaria, cepos de bigornas e açougue, calçamento de ruas e implementos agrícolas, sendo ainda resistente ao ataque de fungos e térmitas.
Alencar \& Magalhães (1979) estudando o poder germinativo de sementes de espécies florestais amazônicas, determinaram para as sementes de angelim pedra uma germinação de $12,5 \%$ em um período de 46 dias, fator limitante para a formação gâmica de mudas dessa espécie, em larga escala.

Várias são as causas da dormência de sementes de espécies florestais. Popinigis (1977), Toledo \& Marcos Filho (1977) classificam a impermeabilidade do tegumento entre as várias causas possíveis. A impermeabilidade do tegumento deve-se à camada de células paliçádicas, com paredes espessas e recobertas por cutícula cerosa que impede a embebição e trocas gasosas entre o meio e o interior da semente. Toledo e Marcos Filho (1977) citam as Leguminosas e as Malváceas como famílias onde se encontram o maior número de espécies cujas sementes são denominadas de duras, isto é com o tegumento descrito, recomendando escarificações mecânicas, químicas ou com solventes para aumento

\footnotetext{
* Instituto Nacional de Pesquisas da Amazônia - INPA/CNPq

* * Departamento de Silvicultura - ESALQ - USP
} 
de porcentagem de germinação e velocidade de emergência.

Pelos tratamentos utilizados e resultados de Souza et al. 1980) chega-se a conclusão de que o tegumento é a causa da dormência de três Leguminosas arbóreas. Carneiro (1976) cita "bracatinga", "flamboyant" e "acácia", espécies pertencentes à família das Leguminosas, cujas sementes possuem duro tegumento.

Examinando-se a semente do "angelim pedra", nota-se um espesso e duro tegumento, sendo assim considerada como hipótese do presente trabalho a impermeabilidade do tegumento responsável pela dormência das sementes dessa espécie. Outros objetivos visam a homogeneização e aumento da porcentagem de germinação, prática de grande interesse silvicultural.

\section{MATERIAL E MÉTODOS}

\section{a) Material}

As sementes, por ocasião do experimento, contavam 12 dias após a coleta. As sementes foram coletadas do chão, de oito árvores matrizes, não sendo anotadas características fenotípicas dessas matrizes. Estas árvores fazem parte de mata tropical úmida de terra firme próxima à estrada da Cidade Nova, Manaus. As sementes foram armazenadas a temperatura de $210^{\circ} \mathrm{C} \pm 2$, não havendo controle da umidade relativa, contando então, por ocasião do experimento, as seguintes características:
- peso de 1000 sementes

$$
(\mathrm{g})=173,75
$$

- $\%$ de umidade $=5,75$

- \% de flutuação em

$$
\text { água }=0,00
$$

Para cada teste adicional, foram escolhidas sementes sadias, pois apresentavam $2,8 \%$ de ataque por larvas de coleópteros, sendo este também o critério de escolha de sementes para os tratamentos, após o qual foram misturadas, com a finalidade de obter-se ao acaso, lotes homogêneos para os tratamentos do experimento.

b) Tratamentos

- Testemunha

$-\mathrm{H}_{2} \mathrm{SO}_{4}, 96 \%, 5,0 \mathrm{~min}$.

$-\mathrm{H}_{2} \mathrm{SO}_{4}, 96 \%, 10,0 \mathrm{~min}$.

$-\mathrm{H}_{2} \mathrm{SO}_{4}, 96 \%, 20,0 \mathrm{~min}$.

$-\mathrm{H}_{2} \mathrm{SO}_{4}, 96 \%, 30,0 \mathrm{~min}$.

$-\mathrm{H}_{2} \mathrm{O}, 80{ }^{\circ} \mathrm{C}, 2,5 \mathrm{~min}$.

$-\mathrm{H}_{2} \mathrm{O}, 80^{\circ} \mathrm{C}, 5,0 \mathrm{~min}$.

$-\mathrm{H}_{2} \mathrm{O}, 80 \circ \mathrm{C}, 10,0 \mathrm{~min}$.

$-\mathrm{H}_{2} \mathrm{O}, 80 \circ \mathrm{C}, 20,0 \mathrm{~min}$.

$-\mathrm{HNO}_{3}, 65 \%, 5,0 \mathrm{~min}$.

- $\mathrm{HNO}_{3}, 65 \%, 10,0 \mathrm{~min}$.

$-\mathrm{HNO}_{3}, 65 \%, 20,0 \mathrm{~min}$.

- $\mathrm{HNO}_{3}, 65 \%, 30,0 \mathrm{~min}$.

$-\mathrm{H}_{2} \mathrm{O}$ ambiente, 13 horas

$-\mathrm{H}_{2} \mathrm{O}$ ambiente, 25 horas

- Escarificação mecânica manual em pedra abrasiva

Os cuidados tomados para cada tratamento foram os seguintes:

1 - lavagens em água corrente à temperatura ambiente e por tem- 
po aproximado de 3 minutos, tendo os objetivos de:

- retirada do excesso de ácido

- igualar as temperaturas dos tratamentos

2 - tomadas de temperatura na aplicação dos tratamentos

- temperatura nas escarificações mecânicas
a) $\mathrm{H}_{2} \mathrm{SO}_{4}$

Durante as exposições: $30^{\circ} \mathrm{C}-$ $31{ }^{\circ} \mathrm{C}$ (possivelmente devida ao baixo teor de umidade).

Durante as lavagens com água, a temperatura máxima atingida foi de $80^{\circ} \mathrm{C}$.

b) $\mathrm{HNO}_{3}$

Tanto durante as exposições, como durante as lavagens a temperatura máxima foi de $31{ }^{\circ} \mathrm{C}$.

3 - As relações volumétricas de tratamentos que assim o exigiam foram de 5: 1 rimento.

c) Local de instalação do expe-

Após os tratamentos, as sementes foram semeadas à profundidade de $0,5 \mathrm{~cm}$ em caixas de madeira, contendo areia lavada como substrato. As caixas estavam ao abrigo de telhas transparentes no galpão da Reserva Florestal. Ducke, lat $03008^{\prime} 05^{\prime}$ S, long. $59052^{\prime}$. W, tipo de clima pela classificação de
Koeppen, Afi (Ribeiro, 1976). As irrigações foram diárias e em número de duas.

d) Tratamentos estatísticos

O delineamento foi o inteiramente casualizado com 4 repetições de 25 sementes, sendo feita a análise de variância com teste " $F$ " e comparação entre as médias pelo teste de Tukey ao nível de $5 \%$ de probabilidade. As porcentagens de germinação foram transformadas para valores de arco seno (Fisher e Yates, 1971) e o índice de velocidade de emergência foi calculado de acordo com Popinigis (1977), de acordo com a fórmula:

$I V E=\sum \begin{aligned} & n o ̣ \text { de plântulas emergi- } \\ & \begin{array}{l}\text { das a cada dia dias transcorridos } \\ \text { da data de semeadura }\end{array}\end{aligned}$

O critério usado para a determinação de semente germinada foi o de considerar-se a emergência do caulículo. $\mathrm{O}$ teste foi interrompido aos 25 dias após a semeadura baseando-se na queda do índice de velocidade de emergência do melhor tratamento.

\section{RESULTADOS}

Os resultados da porcentagem de germinação média e índice de velocidade de emergência por tratamento encontram-se respectivamente nas tabelas 1 e 2 . 
TABELA 1 - Efeito dos Tratamentos Pré-Germinativos na Porcentagem de Germinação nas sementes de Angelim Pedra.

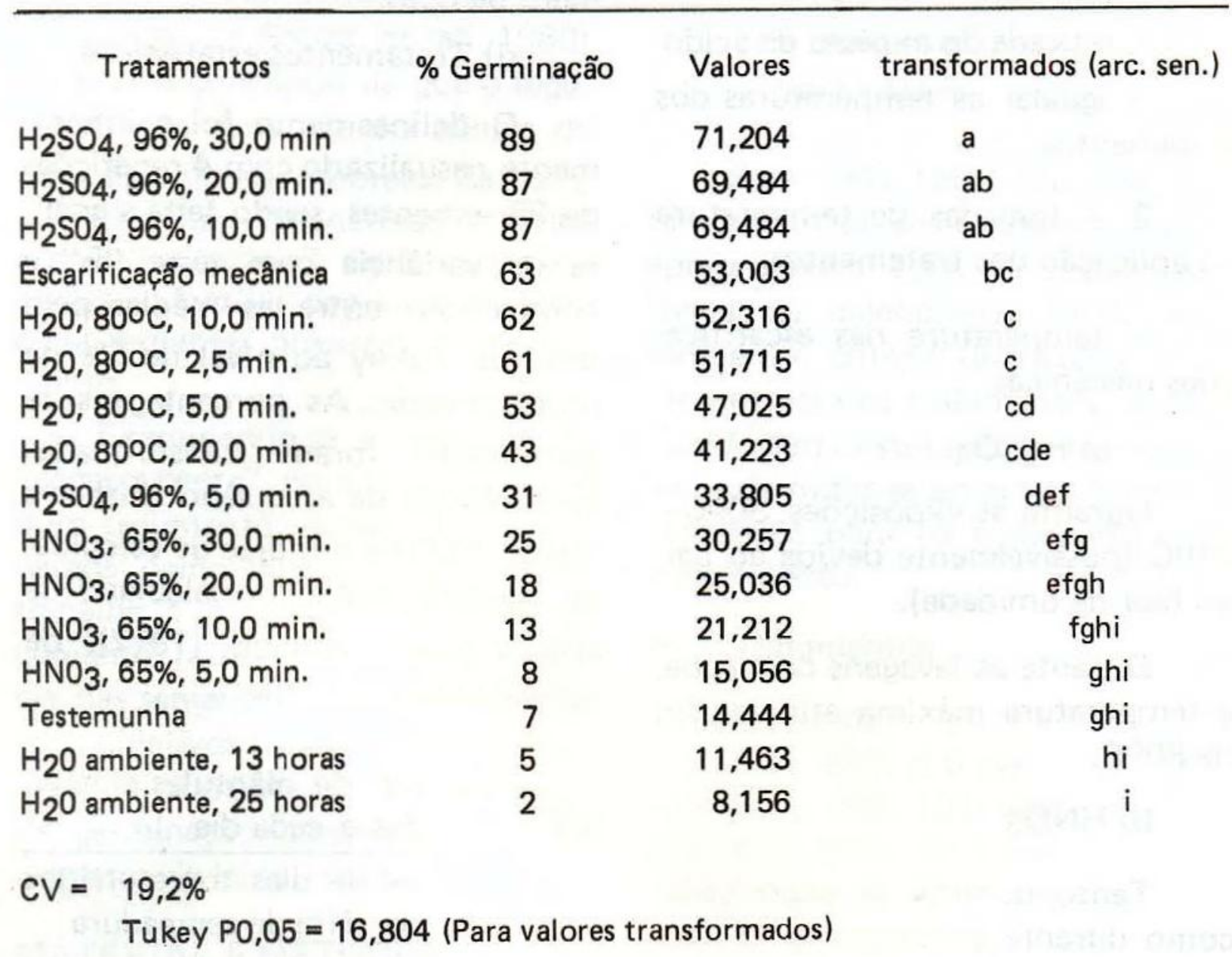

Os tratamentos acompanhados por letras idênticas não diferem es- tatisticamente pelo teste de Tukey ao nível de $5 \%$ de probabilidade.
As tendências para tratamentos que receberam quatro tempos diferentes de exposição encontram-se nas figura 1 (\% de germinação) e 2 (índice de velocidade de emergência).

\section{DISCUSSŌES}

Pelos tratamentos escarificantes químicos $\left(\mathrm{H}_{2} \mathrm{SO}_{4}\right.$ e $\left.\mathrm{HNO}_{3}\right)$ nota-se que a ação dos ácidos e o tem- po de exposição das sementes atuam de forma crescente na porcentagem de germinação ( $\mathrm{V}$. figura 2). Este gráfico mostra que o tempo de exposição a ácidos, age no sentido de aumentar a destruição do tegumento. De fato, observando-se a ação dos ácidos nas sementes nota-se etapas de destruição parcial do tegumento até a destruição total (isto no caso do $\mathrm{H}_{2} \mathrm{SO}_{4}$ ). 
TABELA 2 - Efeito dos tratamentos pré-germinativos na velocidade de emergência em campo nas sementes de Angelim Pedra.

Tratamentos

$\mathrm{H}_{2} \mathrm{SO}_{4}, 96 \%, 20,0$ min.

$\mathrm{H}_{2} \mathrm{SO}_{4}, 96 \%, 30,0$ min.

Escarificação mecânica.

$\mathrm{H}_{2} \mathrm{SO}_{4}, 96 \%, 10,0$ min.

$\mathrm{H}_{2} \mathrm{O}, 80^{\circ} \mathrm{C}, 10,0 \mathrm{~min}$.

$\mathrm{H}_{2} 0,80 \circ \mathrm{C}, 2,5 \mathrm{~min}$.

$\mathrm{H}_{2} \mathrm{O}, 80 \circ \mathrm{C}, 5,0 \mathrm{~min}$.

$\mathrm{H}_{2} \mathrm{SO}_{4}, 96 \%, 5,0 \mathrm{~min}$.

$\mathrm{H}_{2} 0,80 \circ \mathrm{C}, 20 \mathrm{~min}$.

$\mathrm{HNO}_{3}, 65 \%, 30 \mathrm{~min}$.

$\mathrm{HNO}_{3}, 65 \%, 20 \mathrm{~min}$.

$\mathrm{HNO}_{3}, 65 \%, 10 \mathrm{~min}$.

$\mathrm{HNO}_{3}, 65 \%, 50 \mathrm{~min}$.

Testemunha

$\mathrm{H}_{2} \mathrm{O}$ ambiente, 13 horas

$\mathrm{H}_{2} \mathrm{O}$ ambiente
Indice de velocidade de emergência

$3,79 \quad a$

$3,72 \quad a$

2,65 b

$2,69 \quad b$

$1,30 \quad c$

$1,20 \quad$ cd

1,04 cd

1,03 cde

0,87 def

0,65 defgh

$0,51 \quad$ efghi

$0,32 \quad$ hi

$0,24 \quad$ hi

0,16 hi

0,12 hi

$0,05 \quad i$

$$
\begin{aligned}
\mathrm{CV}= & 18,2 \%= \\
& \text { Tukey } \mathrm{P0}, 05=0,58
\end{aligned}
$$

Os tratamentos acompanhados por letras idênticas não diferem es- tatisticamente pelo teste de Tukey ao nível de $5 \%$ de probabilidade.

$\mathrm{O}$ tratamento com $\mathrm{HNO}_{3}$, Ihor tratamento seguido da escarifi$65 \%$, apesar de não ser o mais efi- cação mecânica que permitiu a encaz, mostrou-se bom exemplo di- trada de água para o interior da sedático, tanto na figura 1 como na mente, demonstrando com isso que figura 2, observando-se o aumento pratićamente proporcional entre o tempo de exposição no ácido e comportamento das sementes.

$\mathrm{O} \mathrm{H}_{2} \mathrm{SO}_{4}$, a partir de 10 minutos de exposição mostrou ser o meo tegumento é o fator limitante na germinação (compare-se à testemunha e água à temperatura ambiente).

O efeito térmico da água a $80^{\circ} \mathrm{C}$ mostrou-se satisfatório, con- 


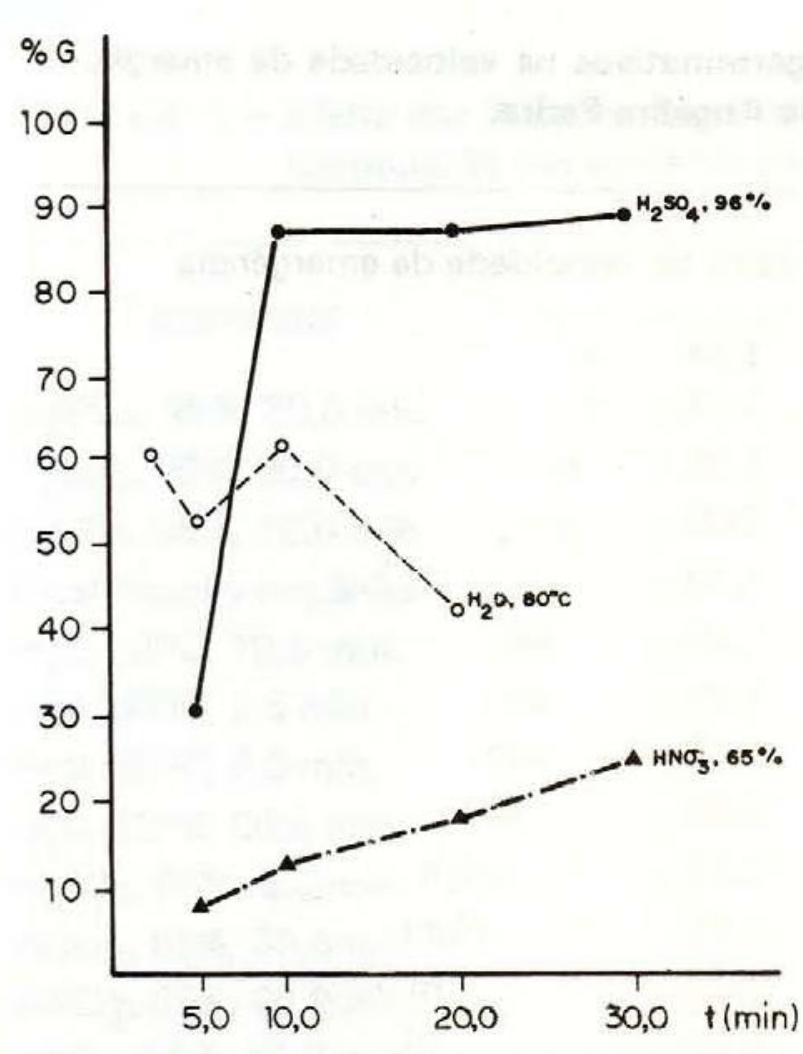

Fig. 1 - Tendências nos tempos de exposição para 3 tratamentos $\left(\mathrm{H}_{2} \mathrm{SO}_{4}\right.$, $\mathrm{HNO}_{3}, \mathrm{H}_{2} \mathrm{O}$ ) agindo na porcentagem de germinação.

cordando o preconizado por Carneiro (1976) referindo-se as Leguminosas. Deste modo, a temperatura agiria na cutícula cerosa das células paliçádicas, eliminando-a total ou parcialmente, sendo este fato em função da temperatura e tempo de exposição.

\section{CONCLUSŌES E RECOMENDAÇÕES}

Apesar de não se ter demonstrado a presença ou não de inibidores de germinação, demonstrou-se que a impermeabilidade do tegumento é o fator limitante que direta ou indiretamente (na presença de inibidores de germinação) age na

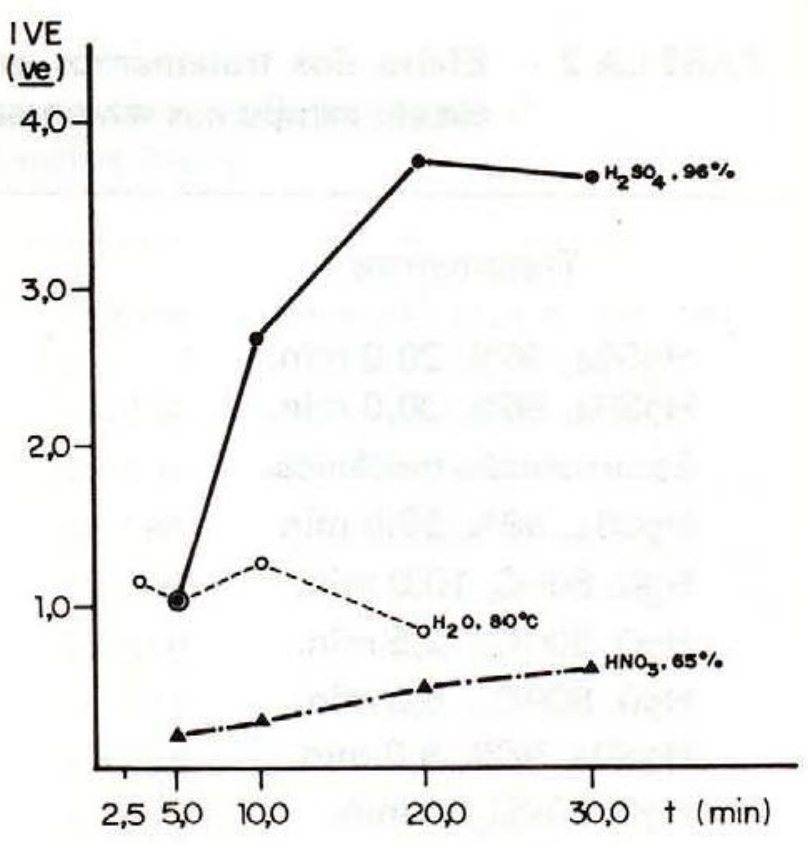

Fig. 2 - Tendências nos tempos de exposição para 3 tratamentos $\left(\mathrm{H}_{2} \mathrm{SO}_{4}\right.$, $\mathrm{HNO}_{3}, \mathrm{H}_{2} \mathrm{O}$ ) agindo no indice de velocidade de emergência.

germinação das sementes de angelim pedra.

Finalmente, recomenda-se para grandes lotes de sementes, a água quente e para pequenos lotes de sementes com valor genético considerável os tratamentos com $\mathrm{H}_{2} \mathrm{SO}_{4}$ a partir de 10 minutos e a escarificação mecânica, devendo ainda este último ser melhor estudado em escarificadores mecanizados elétricos e por vários tempos de escarificação.

\section{SUMMARY}

The "angelim pedra" (Dinizia excelsa Ducke - Leguminosae) is a forest species of the Amazonian Region of economic importance, but is little studied. Its seeds show dormancy and germination heterogeneity, that creates difficulties in seedling formation. 
The authors of the present work studied methods of breaking this seed dormancy, and the influence of seed coat in germination. It is recommended that to break dormancy, scarification with sulfuric acid, mechanical scarification, or thermic action be utilized.

\section{REFERÊNCIAS BIBLIOGRÁFICAS}

ALENCAR, J. C. \& MAGALHÃES, L. M. S.

1979 - Poder germinativo de doze espécies florestais da região de Manaus. Acta Amazonica, 9 (3) : 411 418.

CARNEIRO, J. G. A.

1976 - Métodos para quebra de dormência de sementes. $A$. Semente. Prófloral. p5-11

FISHER, R. A. \& YATES

1971 - Tabelas estatísticas para pesquisa em biologia, medicina e agricultura, Ed. U. S. P. S. Paulo p. 78-9.
LOUREIRO, A.; SILVA, M. F. \& ALENCAR, J. C.

1979 - Essências madeireiras da Amazônia I. INPA. 245 p.

POPINIGIS, F.

1977 - Fisiologia da semente, M. A. - AGIPLAN Brasília 289 p. il.

RIBEIRO, M. N. G.

1976 - Aspectos climatológicos de Manaus. Acta Amazonica, 6 (2) : $229-233$.

SOUZA, S. M. et al.

1980 - Estudos de métodos para superar a dormência de sémentes de Piptadenia obliqua (Pers) Macbr, Pithecellobium parvifolium (Willd) Benth e Cassia excelsa Schard. In: Bol. de Pesquisa, (2) : Petiolina 1-14.

TOLEDO, F. F. \& MARCOS FILHO, J. 1977 - Manual das Sementes Tecnologia da Produção, Ceres, São Paulo 224 p.

(Aceito para publicação em 18/4/83) 